\title{
Pattern and factors associated with cardiovascular diseases among patients attending the cardiac center in Arar City, Northern Saudi Arabia
}

Fatimah Fahad Altaleb ${ }^{1}$, Othman Mashfi Alshammari ${ }^{1}$, Hala Mohammed Alanazi ${ }^{1}$, Dina Anwar Aljaber ${ }^{1}$, Arwa Bader Alanazi ${ }^{1}$, Nagah Mohamed Abo El-Fetoh ${ }^{2}$, Nesreen Ali Mohammed ${ }^{3}$, Hadil Anwar Aljaber ${ }^{4}$

${ }^{1}$ Intern, Northern Border University, Arar, Saudi Arabia

${ }^{2}$ Associate Professor of Community Medicine, Northern Border University, Arar, Saudi Arabia

${ }^{3}$ Lecturer of Community Medicine, Sohag University, Sohag, Egypt

${ }^{4}$ Medical Student, Northern Border University, Arar, Saudi Arabia

Type of article: Original

\begin{abstract}
Background: Cardiovascular diseases (CVD) are among the main causes of premature death and hospital admission worldwide, constituting a great economic burden on health care systems. Additionally, thyroid diseases may exert a deleterious effect on the outcomes of CVD patients.

Aim: This study was conducted to identify the pattern and factors associated with CVD distribution and the relation with thyroid dysfunction in the study population.

Methods: This cross sectional study was conducted on 181 participants in the cardiac center in Arar, Kingdom of Saudi Arabia (KSA), from September 2016 to March 2017. A questionnaire was designed for collecting data about socio-demographic variables, smoking, types of CVD, and thyroid dysfunction among participants.

Results: Findings showed that $42.5 \%$ of the participants were hypertensive, $11.6 \%$ had myocardial infarction, $8.9 \%$ were ischemic and $7.2 \%$ had arrhythmia. The majority of participants $(80.6 \%)$ were euthyroid. In contrast, $13.3 \%$ of the participants had hypothyroidism and $6.1 \%$ were hyperthyroid. Most of the studied factors had no significant effect on CVD distribution while smoking showed a remarkable variation among patients with different CVD types ( $\mathrm{p}=0.013$ ). Data were analyzed by SPSS version 15, using descriptive statistics and Chisquare test.

Conclusion: Our findings indicated the urgent need for stressing on tobacco use control measures and increasing public awareness about hazards of tobacco especially among CVD patients.
\end{abstract}

Keywords: Cardiovascular diseases; Pattern, Smoking, Thyroid dysfunction

\section{Introduction}

Cardiovascular diseases (CVD) are among the main causes of premature death $(1,2)$ and by the year 2030, cardiovascular diseases related mortality is expected to increase up to 25 million, mainly from heart disease and stroke (3). In addition, cardiovascular diseases are considered the most common cause of hospital admission worldwide resulting in a great economic burden on health care systems (2). Therefore, prevention of these diseases and early detection of factors that may contribute to their occurrence is considered a public health necessity that should be taken into consideration (4). A variety of factors may play a role in the development of cardiovascular diseases. These factors can be classified into modifiable and non-modifiable risk factors. The modifiable factors, including smoking, diet and sedentary life, can be prevented and controlled leading to a significant reduction in CVD and associated mortalities. The non-modifiable factors include gender, age, and family history (5). Thyroid hormones exert a remarkable effect on the cardiovascular system function and cardiac hemodynamic $(6,7)$. This effect is more likely to be age-dependent as in certain age groups, thyroid diseases have been suggested to be one of the main cardiovascular risk factors resulting in cardiovascular morbidity and mortality (8). The role of thyroid

\section{Corresponding author:}

Fatimah Fahad Altaleb, Northern Border University, Arar, Saudi Arabia.

Tel.: 0551578890, Email: Leaderz_hf@hotmail.com

Received: July 14, 2017, Accepted: August 21, 2017, Published: October 2017

iThenticate screening: August 21, 2017, English editing: September 14, 2017, Quality control: September 16, 2017

(C) 2017 The Authors. This is an open access article under the terms of the Creative Commons Attribution-NonCommercialNoDerivs License, which permits use and distribution in any medium, provided the original work is properly cited, the use is non-commercial and no modifications or adaptations are made. 
dysfunction in the occurrence of cardiovascular diseases have been suggested to occur through the resulting changes in the normal cardiac function, myocardial oxygen demand, vascular resistance, and lipid profile (9). A minor change in the thyroid function impacts ventricular func $\neg$ tion, serum cholesterol levels and results in increased inflammatory burden and endothelial dysfunction $(10,11)$. Additionally, thyroid dysfunction is associated with elevated blood pressure, arrhythmia and disturbed systolic and diastolic cardiac function (12), and has been suggested to play a role in atherosclerosis and arterial stiffness (11). Furthermore, thyroid diseases may exert a deleterious effect on the outcomes in patients with cardiovascular diseases and can be considered as a predictor for cardiovascular deaths (12). Globally, thyroid gland dysfunction is among the most common endocrine disorders. It was estimated that 300 million people worldwide are suffering from thyroid dysfunction (13) and females are more affected than males which may be attributed to the effect of estrogen and progesterone $(13,14)$. So, this study was conducted to identify the pattern and factors associated with the distribution of cardiovascular diseases among patients attending the cardiac center in Arar city in the Northern Borders Province of the Kingdom of Saudi Arabia and the relation with thyroid dysfunction in the study population.

\section{Material and Methods}

\subsection{Study design and participants}

The current study is a cross sectional study conducted in the cardiac center in Arar city in the Northern Borders Province of the Kingdom of Saudi Arabia, during the period from September 2016 to March 2017. The current study included 181 individuals attending the cardiac center in Arar city in the Northern Borders Province of the Kingdom of Saudi Arabia. The center was reviewed regularly during the study period, and the participants were selected by systemic random sampling procedure, and were invited to participate in the study and included in the study after taking an informed consent. Each person was interviewed separately, and their files were examined to collect the needed data and fill out the questionnaires. The cardiac center provides services in an acceptable atmosphere of both privacy and confidentiality. Exclusion criteria included patients who refused to participate in the study.

\subsection{Data Collection}

Collecting patients' data was conducted through interviewing the patients included in the study and reviewing their medical files. A predesigned questionnaire was used for data collection, and included inquiries about sociodemographic data of the studied patients, smoking, types of cardiovascular diseases and thyroid dysfunction among them.

\subsection{Ethical consideration}

This study was reviewed and approved by the Research Ethics Committee of Faculty of Medicine, Northern Border University. Written informed consent after explaining the purpose of the study was obtained from all patients who participated in the study. The questionnaires used in data collection were anonymous and confidentiality of data was assured.

\subsection{The statistical analysis}

The statistical analysis was carried out using SPSS version 15. Sample characteristics were summarized as numbers and percentages for qualitative variables. Chi-Square test was used for testing the association between sociodemographic variables, smoking and thyroid dysfunction and pattern of distribution of cardiovascular diseases among the studied population. A 5\% level was chosen as a level of statistical significance in all statistical tests used in the study.

\section{Results}

The current study included 181 participants who attended the cardiac center in Arar, KSA, during the study period and agreed to participate in the study. There were more females than males $(55.2 \%$ vs. $44.8 \%)$. The patients who were younger than 60 years old represented $39.2 \%$ of the study population. More than one-third of the individuals (34.3\%) were between 60 and 70 years of age, $19.9 \%$ were between 70 and 80 years of age, and only $6.6 \%$ were older than 50 years. Regarding marital status, $66.3 \%$ of the respondents were married, $28.7 \%$ were widows, $3.3 \%$ were divorced and 1.7 were single. More than two thirds of the respondents were nonsmokers and more than one fifth $(22.1 \%)$ of them were ex-smokers while only $9.4 \%$ were current smokers at the time of the study (Table 1 ). According to our findings, $42.5 \%$ of the participants were hypertensive, $11.6 \%$ had myocardial infarction, $8.9 \%$ had ischemic heart diseases and $7.2 \%$ suffered from arrhythmia. Regarding thyroid dysfunction among the studied population, the majority of the studied population (80.6\%) had normal thyroid function. On the other hand, $13.3 \%$ of the participants had hypothyroidism and $6.1 \%$ of them had hyperthyroidism. Table 2 describes the relationship 
between thyroid diseases and cardiovascular diseases among the studied population. As shown by the presented data, more than half (54.5\%) of the hyperthyroid patients were hypertensive and $18.2 \%$ of them had ischemic heart diseases. Hypertension was found in $37.5 \%$, and $42.5 \%$ of patients who suffered from hypothyroidism and euthyroid participants respectively. Less than one fifth (16.7\%) of participants with hypothyroidism had myocardial infarction compared to $(9.1 \%)$ of hyperthyroid patients and $(11 \%)$ of participants with normal thyroid function. Arrhythmia was found in higher proportions of hyperthyroid (9.1) and hypothyroid (8.3\%) compared to euthyroid (6.8\%) participants. However, this difference was statistically insignificant $(\mathrm{p}=0.751)$. Concerning the relationship between sociodemographic variables, smoking status and different types of cardiovascular diseases, Table 3 shows that females were more likely to be suffering from hypertension and arrhythmia $(61 \%, 69.2 \%$ respectively) compared to males $(39 \%, 30.8 \%$ respectively). On the other hand, males were found to be more suffering from myocardial infarction and ischemic heart diseases $(61.9 \%, 68.8 \%$ respectively) compared to females with a statistically insignificant difference $(\mathrm{p}=0.078)$. About one third $(32.5 \%)$ of hypertensive patients were younger than 60 years old and participants in the $60-70$ years age group represented $36.4 \%$ of hypertensive patients. More than one third (38.1\%) of myocardial infarction patients were in the $70-80$ years age group and patients who were $<60$ years old represented (42.9\%) of them. Patients younger than sixty years old represented $37.5 \%$ and $46.2 \%$ of ischemic and arrhythmic cases respectively. This difference was statistically insignificant $(p=0.052)$. Moreover, there was no significant difference between different marital status groups regarding pattern of cardiovascular diseases as none of the studied single patients suffered from cardiovascular diseases while most of the affected patients with any of the studied cardiovascular diseases were married. As regards smoking, one quarter of the ischemic patients were current smokers. About half (47.6\%) of myocardial infarction patients were either current smokers or ex-smokers. More than one third (38.5\%) of patients with arrhythmia were ex-smokers. This difference was statistically significant $(\mathrm{p}=0.013)$.

Table 1. Sociodemographic characteristics and smoking among the studied population, Arar, 2017

\begin{tabular}{|l|l|l|l|}
\hline Variables & & n (total: 181) & $\%$ \\
\hline Age (years) & $<60$ & 71 & 39.2 \\
\cline { 2 - 4 } & $60-70$ & 62 & 34.3 \\
\cline { 2 - 4 } & $70-80$ & 36 & 19.9 \\
\cline { 2 - 4 } & $>80$ & 12 & 6.6 \\
\hline \multirow{5}{*}{ Mex } & Female & 100 & 55.2 \\
\cline { 2 - 4 } & Male & 81 & 44.8 \\
\hline \multirow{5}{*}{ Sarital Status } & Married & 120 & 66.3 \\
\cline { 2 - 4 } & Widowed & 52 & 28.7 \\
\cline { 2 - 4 } & Single & 3 & 1.7 \\
\cline { 2 - 4 } & Divorced & 6 & 3.3 \\
\hline & Non-smoker & 124 & 68.5 \\
\cline { 2 - 4 } & Smoker & 17 & 22.1 \\
\cline { 2 - 4 } & Ex-smoker & 40 & \\
\hline
\end{tabular}

Table 2. The relationship between thyroid diseases and cardiovascular diseases among the studied population, Arar, 2017

\begin{tabular}{|l|l|l|l|l|}
\hline \multirow{2}{*}{ Cardiovascular diseases } & \multicolumn{2}{|l|}{ Thyroid dysfunction; $\mathrm{n}(\%)$} & \multirow{2}{*}{ Total $(\mathrm{n}=181) ; \mathrm{n}(\%)$} \\
\cline { 2 - 4 } & Hyperthyroidism (n=11) & $\begin{array}{l}\text { Hypothyroidism } \\
(\mathrm{n}=24)\end{array}$ & Euthyroid $(\mathrm{n}=146)$ & \\
\hline Hypertension & $6(54.5)$ & $9(37.5)$ & $62(42.5)$ & $77(42.5)$ \\
\hline Myocardial Infarction & $1(9.1)$ & $4(16.7)$ & $16(11.0)$ & $21(11.6)$ \\
\hline Ischemic heart diseases & $2(18.2)$ & $3(12.5)$ & $11(7.5)$ & $16(8.8)$ \\
\hline Arrhythmia & $1(9.1)$ & $2(8.3)$ & $10(6.8)$ & $13(7.2)$ \\
\hline No CVD & $1(9.1)$ & $6(25.0)$ & $47(32.2)$ & $54(29.8)$ \\
\hline \multicolumn{2}{|l|}{ Chi-Square $=5.05 ; p$-value $=0.751$} & \\
\hline
\end{tabular}


Table 3. The relationship between sociodemographic variables, smoking status, and cardiovascular diseases among the studied population, Arar, 2017

\begin{tabular}{|c|c|c|c|c|c|c|c|c|c|}
\hline \multicolumn{2}{|l|}{ Variables } & \multicolumn{5}{|c|}{ Cardiovascular Diseases } & \multirow{2}{*}{$\begin{array}{l}\text { Total } \\
(\mathrm{n}=181)\end{array}$} & \multirow{2}{*}{$\begin{array}{l}\text { Chi- } \\
\text { Square }\end{array}$} & \multirow{2}{*}{$\begin{array}{l}\mathrm{P} \text { - } \\
\text { value }\end{array}$} \\
\hline & & $\begin{array}{l}\text { Hypertension } \\
(\mathrm{n}=77)\end{array}$ & $\begin{array}{l}\text { Infarction } \\
(\mathrm{n}=21)\end{array}$ & $\begin{array}{l}\text { Ischemia } \\
(\mathrm{n}=16)\end{array}$ & $\begin{array}{l}\text { Arrhythmia } \\
(\mathrm{n}=13)\end{array}$ & \begin{tabular}{|l|}
$\begin{array}{l}\text { No CVD } \\
(\mathrm{n}=54)\end{array}$ \\
\end{tabular} & & & \\
\hline \multirow[t]{2}{*}{ Sex } & Female & $47(61.0)$ & $8(38.1)$ & $5(31.2)$ & $9(69.2)$ & $31(57.4)$ & $100(55.2)$ & \multirow[t]{2}{*}{8.40} & \multirow[t]{2}{*}{0.078} \\
\hline & Male & $30(39.0)$ & $13(61.9)$ & $11(68.8)$ & $4(30.8)$ & $23(42.6)$ & $81(44.8)$ & & \\
\hline \multirow[t]{4}{*}{ Age (years) } & $<60$ & $25(32.5)$ & $9(42.9)$ & $6(37.5)$ & $6(46.2)$ & $25(46.3)$ & $71(39.2)$ & \multirow[t]{4}{*}{20.88} & \multirow[t]{4}{*}{0.052} \\
\hline & $60-70$ & $28(36.4)$ & $4(19.0)$ & $4(25.0)$ & $6(46.2)$ & $20(37.0)$ & $62(34.3)$ & & \\
\hline & $70-80$ & $18(23.4)$ & $8(38.1)$ & $6(37.5)$ & $0(0.0)$ & $4(7.4)$ & $36(19.9)$ & & \\
\hline & $>80$ & $6(7.8)$ & $0(0.0)$ & $0(0.0)$ & $1(7.7)$ & $5(9.3)$ & $12(6.6)$ & & \\
\hline \multirow{4}{*}{$\begin{array}{l}\text { Marital } \\
\text { status }\end{array}$} & Widow & $26(33.8)$ & $4(19.0)$ & $3(18.8)$ & $4(30.8)$ & $15(27.8)$ & $52(28.7)$ & \multirow[t]{4}{*}{13.32} & \multirow[t]{4}{*}{0.34} \\
\hline & Single & $0(0.0)$ & $0(0.0)$ & $0(0.0)$ & $0(0.0)$ & $3(5.6)$ & $3(1.7)$ & & \\
\hline & Married & $50(64.9)$ & $16(76.2)$ & $13(81.2)$ & $8(61.5)$ & $33(61.1)$ & $120(66.3)$ & & \\
\hline & Divorced & $1(1.3)$ & $1(4.8)$ & $0(0.0)$ & $1(7.7)$ & $3(5.6)$ & $6(3.3)$ & & \\
\hline \multirow[t]{3}{*}{$\begin{array}{l}\text { Smoking } \\
\text { status }\end{array}$} & $\begin{array}{l}\text { Non- } \\
\text { smoker }\end{array}$ & $61(79.2)$ & $11(52.4)$ & $10(62.5)$ & $8(61.5)$ & $34(63.0)$ & $124(65.5)$ & \multirow[t]{3}{*}{19.32} & \multirow[t]{3}{*}{0.013} \\
\hline & Smoker & $4(5.2)$ & $5(23.8)$ & $4(25.0)$ & $0(0.0)$ & $4(7.4)$ & $17(9.4)$ & & \\
\hline & $\begin{array}{l}\text { Ex- } \\
\text { smoker }\end{array}$ & $12(15.6)$ & $5(23.8)$ & $2(12.5)$ & $5(38.5)$ & $16(29.6)$ & $40(22.1)$ & & \\
\hline
\end{tabular}

\section{Discussion}

The current study included 181 individuals attending the cardiac center in Arar city in the Northern Borders Province of Kingdom of Saudi Arabia were included in the study. On assessment of the pattern of cardiovascular diseases (CVD) among the studied population data, $42.5 \%$ of the participants were found to have hypertension, $11.6 \%$ had myocardial infarction, $8.9 \%$ had ischemic heart diseases and $7.2 \%$ suffered from arrhythmia. These findings are higher than the results of another study (15) and found that dysrhythmia patients represented only $1.8 \%$ and ischemic heart diseases was found in only $0.5 \%$ of the studied population. A possible explanation is that the latter study included patients with chronic kidney disease with the most common cardiovascular diseases among them being hypertrophy, pericarditis and heart failure. Another study (16) revealed that the most prevalent types were peripheral vascular diseases and cerebrovascular diseases. This study included diabetic patients with more liability to peripheral vascular diseases and this explains the discrepancy in the pattern of CVD. In support of our findings, another study (17) found that the most common disease (45\%) among the studied population was hypertension. In other studies done in developing countries, hypertension was found to be the first or the second leading cause of cardiovascular diseases $(18,19)$. Hypothyroidism was found in $13.3 \%$ of the respondents in the current study and $6.1 \%$ of the current study population had hyperthyroidism. This is not in line with the findings of another study (20) that reported the prevalence of hypothyroidism among the study population was $22 \%$. Furthermore, the same study concluded that hypothyroidism was found in $26 \%$ of ischemic patients and $18 \%$ of hypertensive patients, and these proportions were higher than the findings of the current study. The latter study was conducted among the elderly population and this may explain the higher rates revealed by this study as the prevalence of hypothyroidism shows a significant increase in the older age classes (21). A study (22) conducted in heart failure clinics concluded that 4.2\% had hyperthyroidism and 67.3\% had hypothyroidism. Another study (23) revealed that more than one third $(38.5 \%)$ of the studied hypertensive patients had hypothyroidism which is much higher than what was concluded by the current study, as only 9 of the 77 hypertensive patients had hypothyroidism. The current study found that $8.3 \%$ of hypothyroid patients and $9.1 \%$ of patients with hyperthyroidism were arrhythmic. Ischemic heart diseases were found in $12.5 \%$ and $18.2 \%$ of patients who suffered from hypothyroidism and hyperthyroid participants respectively. These findings are much lower than what was reported in a study conducted by (1) where arrhythmia was found in 34.6\% of patients with hypothyroidism and 32.7\% of hyperthyroid patients. In addition, ischemic heart diseases were found in 50\% of hypothyroid patients and $46.9 \%$ of patients with hyperthyroidism. This difference may be explained by the large sample included in the latter study compared to the current study. As illustrated by the current study, the pattern of cardiovascular diseases distribution in the studied population showed no significant difference between males and females. Contrary to these results, another study (24) reported that there was a statistically significant difference between males and females regarding the cardiac disease distribution. The mean age of the studied males with most of the studied cardiac disease in the latter study was higher than that of the females which may explain the higher rates of most of the cardiac diseases among the studied males. Furthermore, age had no effect on the pattern of the cardiovascular diseases in the current study which is not in agreement with the findings of that study (24) which revealed a significant difference between 
different types of cardiac diseases regarding the ages of the affected patients. An explanation is that the latter study included patients with rheumatic heart disease (RHD) with lower ages while no RHD patients were observed in the current study. Regarding the relation between smoking status and the distribution of cardiovascular diseases in the studied population, smoking status of the studied patients showed a remarkable variation among patients with different cardiovascular disease types with a statistically significant difference which is supported by the findings of another study (25). Regarding the study limitations, we should say that other factors which may be associated with the pattern of cardiovascular diseases were not covered by the current study focusing on the relation with certain socio-demographic variables, smoking and thyroid dysfunction.

\section{Conclusions}

The current study revealed that $42.5 \%$ of the participants were hypertensive, $11.6 \%$ had myocardial infarction, $8.9 \%$ had ischemic heart diseases and $7.2 \%$ suffered from arrhythmia. The majority of the studied population (80.6\%) had normal thyroid function. On the other hand, about one fifth of the studied population $(19.4 \%)$ had thyroid dysfunction (13.3\% of the participants had hypothyroidism and $6.1 \%$ of them had hyperthyroidism). Thyroid dysfunction may add to cardiovascular risk and assessment of thyroid function is recommended especially in a highrisk population. Most of the studied factors had no significant effect on the pattern of the studied cardiovascular diseases and their distribution among the studied population. On the other hand, smoking status of the studied patients showed a remarkable variation among patients with different cardiovascular disease types with a statistically significant difference. One quarter of the ischemic patients and $23.8 \%$ of patients with myocardial infarction were current smokers which indicates the urgent need for highlighting tobacco use control measures and focusing on increasing public awareness about hazards of tobacco especially among cardiovascular disease patients.

\section{Acknowledgments:}

The authors would like to acknowledge all patients participating in the study and the staff in the cardiac center in Arar for their kind cooperation.

\section{Conflict of Interest:}

There is no conflict of interest to be declared.

\section{Authors' contributions:}

All authors contributed to this project and article equally. All authors read and approved the final manuscript.

\section{References:}

1) Iervasi G, Molinaro S, Landi P, Taddei MC, Galli E, Mariani F, et al. Association between increased mortality and mild thyroid dysfunction in cardiac patients. Archives of internal medicine. 2007;167(14):1526-32. Doi: 10.1001/archinte.167.14.1526, PMid: 17646607

2) Eaton CB. Traditional and emerging risk factors for cardiovascular disease. Primary Care: Clinics in Office Practice. 2005;32(4):963-76. Doi: 10.1016/j.pop.2005.09.009, PMid: 16326222

3) Khuwaja AK, Lalani S, Azam IS, Ali BS, Jabbar A, Dhanani R. Cardiovascular Disease-Related Lifestyle Factors among People with Type 2 Diabetes in Pakistan: A Multicentre Study for the Prevalence, Clustering, and Associated Sociodemographic Determinants. Cardiology Research and Practice. 2011;2011:8. Doi: 10.4061/2011/656835, PMid: 21837274, PMCid: PMC3152959

4) Wang J, Ma X, Qu S, Li Y, Han L, Sun X, et al. High prevalence of subclinical thyroid dysfunction and the relationship between thyrotropin levels and cardiovascular risk factors in residents of the coastal area of China. Experimental \& Clinical Cardiology. 2013;18(1):e16. PMid: 24294042, PMCid: PMC3716495

5) Jamil NF, Gahni JA. Risk factors for ischemic heart disease among patients admitted to coronary care unit (CCU) in Al-Hussain Hospital in Karballa. Iraqi Journal Of Medical Sciences. 2011;9(3):240-6.

6) Danzi S, Klein I. Thyroid disease and the cardiovascular system. Endocrinology and metabolism clinics of North America. 2014;43(2):517-28. Doi: 10.1016/j.ecl.2014.02.005, PMid: 24891175

7) Fazio S, Palmieri EA, Lombardi G, Biondi B. Effects of thyroid hormone on the cardiovascular system. Recent progress in hormone research. 2004;59(1):31-50. Doi: 10.1210/rp.59.1.31, PMid: 14749496

8) Shinkov A, Borissova A-M, Kovatcheva R, Vlahov J, Dakovska L, Atanassova I, et al. Thyroid dysfunction and cardiovascular risk factors in Bulgarian adults. Open Medicine. 2013;8(6):742-8. Doi: 10.2478/s11536-013-0235-9

9) Klein I, Ojamaa K. Thyroid hormone and the cardiovascular system. New England Journal of Medicine. 2001;344(7):501-9. Doi: 10.1056/NEJM200102153440707, PMid: 11172193 
10) Qari FA. Thyroid hormone profile in patients with acute coronary syndrome. Iranian Red Crescent Medical Journal. 2015;17(7).

11) Tatar E, Demirci MS, Kircelli F, Gungor O, Turan MN, Ok ES, et al. Association of insulin resistance with arterial stiffness in nondiabetic peritoneal dialysis patients. International urology and nephrology. 2012;44(1):255-62. Doi: 10.1007/s11255-011-9984-z, PMid: 21643643

12) Biondi B, Fazio S, Palmieri EA, Carella C, Panza N, Cittadini A, et al. Left ventricular diastolic dysfunction in patients with subclinical hypothyroidism. The Journal of Clinical Endocrinology \& Metabolism. 1999;84(6):2064-7. Doi: 10.1210/jcem.84.6.5733, PMid: 10372711

13) Nimmy N, Aneesh P, Narmadha M, Udupi R, Binu K. A survey on the prevalence of thyroid disorder induced by demography and food habits in South Indian population. Indian Journal of Pharmacy Practice. 2012;5(2).

14) Deokar P, Nagdeote A, Lanje M, Basutkar D. Prevalence of thyroid disorders in a tertiary care center. International Journal of Current Research and Review. 2016;8(9):26.

15) Babua C, Kalyesubula R, Okello E, Kakande B, Sebatta E, Mungoma M, et al. Pattern and presentation of cardiac diseases among patients with chronic kidney disease attending a national referral hospital in Uganda: a cross sectional study. BMC nephrology. 2015;16(1):126. Doi: 10.1186/s12882-015-0128-z, PMid: 26238594, PMCid: PMC4522958

16) Ferguson $T$, Tulloch-Reid MK, Younger N, Wright-Pascoe R, Boyne M, McFarlane S, et al. Cardiovascular disease among patients attending a specialist diabetes clinic in Jamaica. Res Rep Clin Cardiol. 2011;2:41-50. Doi: 10.2147/RRCC.S14779

17) Owusu IK, Adu-Boakye Y. Prevalence and aetiology of heart failure in patients seen at a teaching hospital in Ghana. Journal of Cardiovascular Diseases \& Diagnosis. 2013.

18) Mamo Y, Oli K. Trends of acute myocardial infarction admissions over a decade, Tikur Anbessa Hospital. Ethiopian medical journal. 2001;39(3):193-202. PMid: 11921550

19) Maru M. The changing pattern of cardiovascular diseases in Ethiopia. East African medical journal. 1993;70(12):772-6. PMid: 8026350

20) Mohsen M. Eldarawy, Nearmeen M. Rashad, Ashraf A. Hammam, Fady M. Wadea, Tarek M.H. Ibrahim, Ahmed Kh. Alkolaly, et al. Prevalence of subclinical hypothyroidism in elderly patients with cardiovascular disease. Int J Adv Res. 2016;4(12):1954-61. Doi: 10.21474/IJAR01/2607

21) Bremner AP, Feddema P, Leedman PJ, Brown SJ, Beilby JP, Lim EM, et al. Age-related changes in thyroid function: a longitudinal study of a community-based cohort. The Journal of Clinical Endocrinology \& Metabolism. 2012;97(5):1554-62. Doi: 10.1210/jc.2011-3020, PMid: 22344200

22) Shafran D, Isaac DL. Assessment and Treatment of Thyroid Function in Heart Failure Clinics-Incidence of Abnormal Thyroid Function and Impact on Heart Failure Decompensation. University of Toronto Medical Journal. 2012;89(3):154-9.

23) Jayalal JA, Selwyn T, David T. Study Of Thyroid Dys Function In Metabolic Syndrome In Tamilnadu. International Journal of Recent Scientific Research. 2015;6(4):3702-8.

24) Habte B, Alemseged F, Tesfaye D. The Pattern of Cardiac Diseases at the Cardiac Clinic of Jimma University Specialised Hospital, South West Ethiopia. Ethiopian Journal of Health Sciences. 2010;20(2):99-105.

25) Sumartono W, Sirait AM, Holy M, Thabrany H. Smoking and socio-demographic determinant of cardiovascular diseases among males $45+$ years in Indonesia. International journal of environmental research and public health. 2011;8(2):528-39. Doi: 10.3390/ijerph8020528, PMid: 21556201, PMCid: PMC3084476 